\title{
O HORIZONTE E O “RITO DE CIDADE”
}

\section{Myriam Bahia Lopes ${ }^{1}$}

\begin{abstract}
Resumo: O texto acompanha as transformações da noção de horizonte e mantém o ritmo dado pelo ponto, o início da cidade e o seu contraponto, que se situa no futuro desse passado. Ele visa mostrar o processo de espacialização e de subjetivação dos corpos na cidade de Belo Horizonte relacionando-o a um contexto sócio-sensorial e técnico em mutação.

Palavras-Chave: Horizonte, Cidade, Paisagem, História.
\end{abstract}

Resumé: Le texte suit les transformations de la notion d'horizon et maintien le rythme donné par le point, les origines de la ville et son contrepoint que se situe dans son futur du passé. II indique le procès d'espacialisation et de subjectivation des corps à la ville de Belo Horizonte et reprend un contexte à la fois, social, ensoriel et technique en mutation.

Mots-Clès: Horizon, Ville, Paysage, Histoire.

O artigo visa identificar e analisar entre outros, na obra de Carlos Drummond de Andrade alguns trechos que tratem da montanha, do horizonte, do limite, da relação da paisagem interior/exterior e da mineração. $A$ partir da década de 1970 o horizonte que denomina a capital mineira provoca paradoxalmente em seus habitantes a angustiante experiência de ter de se confrontar com a sua dissolução. Buscamos acompanhar as transformações da noção de horizonte e compará-las mantendo o ritmo dado pelo ponto, o início da cidade e de seu contraponto, que se situa no futuro desse passado e mostrar o processo de espacialização e de subjetivação dos corpos na cidade relacionando-o a um contexto sócio-sensorial e técnico em mutação. A escolha desse autor passa pelas motivações que dizem respeito de um lado, à importância de sua produção na literatura brasileira e mineira e de outro, à sua longa experiência no Departamento de Patrimônio Histórico Nacional (DPHAN) desde 1945 e onde se tornou chefe da Seção de História, na Divisão de Estudos e Tombamento.

\section{DESEJO DO HORIZONTE}

Guatari vê:

1 Professora Adjunta do Dep. de Análise Crítica e Histórica da Arquitetura e do Urbanismo (ACR) da Escola de Arquitetura e Urbanismo (EA) da Universidade Federal de Minas Gerais (UFMG); Coordena o Núcleo de História da Ciência e da Técnica (NEHCIT). Endereço eletrônico: mybahlo@yahoo.com.br. Sítio de internet: http://www.arq.ufmg.br/nehcit. 
O inconsciente antes como algo que se derramaria um pouco em toda a parte ao nosso redor, bem como nos gestos, nos objetos quotidianos ... e nos grandes problemas do momento ... Logo, um inconsciente trabalhando tanto no interior dos indivíduos, na sua maneira de perceber o mundo, de viver seus corpos, seu território, seu sexo, quanto no interior do casal, da família, da escola, do bairro" [...] "um inconsciente voltado para o futuro, um inconsciente cuja trama não seria senão o próprio possível, o possível à flor da linguagem, mas também o possível à flor da pele, à flor do socius, à flor do cosmos (GUATTARI, 1988, p. 9-10).

O horizonte na pesquisa é recortado a partir da complexa relação de desejo dos habitantes da capital mineira.

O desejo de cidade e o eu lírico: "A cidade me vive"

Para Márcio Roberto Soares Dias:

É interessante notar como Carlos Drummond de Andrade, apenas legando ao verbo a transitividade que, no contexto, não seria admitida, consegue ... estabelecer a síntese quase perfeita do consórcio entre homem ... e cidade. Espaço, pessoa, tempo ("Nessa cidade (eu) vivo há 40 anos").

Na sequência das frases temos "Vivo nesta cidade", "vivo esta cidade" e enunciando o discurso lírico "a cidade me vive" (DIAS, 2006, p. 114).

Por sua vez Guattari (1988, p. 12) nos chama a atenção sobre o agenciamento territorial de enunciação.

O afeto da subjetividade territorial vê-se habitado por um horizonte que está além do tempo discursivo (o tempo marcado pelos relógios sociais) uma duração eternitária que escapa à alternativa lembrança-esquecimento. 0 território existencial faz-se aqui, simultaneamente, terra natal, pertencimento de mim, adesão ao clã, efusão cósmica.

Miguel Wisnik aponta em "Lanterna Mágica” publicada em Alguma poesia, que nele: "o mundo é, de fato, um leque gradual de cidades em meio às quais se entretém o ser Brasil, estando Belo Horizonte num lugar de fronteira entre a província, a província da província, a capital da capital". Para Drummond nesse poema, "Sabará - "A dois passos da cidade importante/ A cidadezinha está calada, entrevada./ (Atrás daquele morro, com vergonha de trem)".

Nesse movimento de torsão sobre si mesmo, o mundo se dá no primeiro momento, através da escalada do labor teórico e tecnológico que domina toda a escala da existência até o fundo inconsciente da terra (que é sono, rancor e minério) (WISNIK, NOVAES, 2005, p. 40). 


\section{O HORIZONTE E OS SEUS RECORTES}

Na proposta de Benjamin encontramos o convite para "atravessar o passado com a intensidade de um sonho, a fim de experimentar o presente como o mundo de vigília, ao qual o sonho se refere" ${ }^{2}$. A partir da década de 1970 o horizonte que denomina a capital mineira provoca paradoxalmente em seus habitantes a angustiante experiência de ter de se confrontar com a sua dissolução. Recortamos o período 1890-2010 e os marcos temporais de 1890, 1920, 1940, 1970 e 2010 que delimitam os intervalos nos quais observamos um processo de transformação no ritmo, percepção, representação e agenciamento da vida urbana e que interessa-nos estudar a partir da relação da cidade com a serra e o horizonte.

E destacamos que para Baldine Saint-Girons em seu prefácio do livro de Celine Flécheux, o horizonte "é mais que uma imagem e menos que um conceito" (FLÉCHEUX, 2009, p. 9). O horizonte se produz e se relaciona com a estrutura interna da psique. "O horizonte físico e o horizonte mental se condicionam reciprocamente" apesar de manter entre si uma relativa interdependência" (idem, p. 33).

\section{HISTÓRIA E FICÇÃO}

De um lado e na compania de autores tão variados como, Walter Benjamin, Michel de Certeau, Anne Cauquelin, Maria Stella Bresciani, Flora Sussekind e Luiz Costa Lima, interessa-nos analisar a ficção como um processo singular de produção textual. De outro criticamos o uso que alguns historiadores, entre os quais citamos Sidney Challoub, fazem do texto ficcional e que implica no gesto de isolar imagens e sem mediação incorporálas ao texto de história, fixando-as para confrontá-las com aquilo que designam ser os "fatos" ou "a realidade". Recusamos esse posicionamento que produz um combate imaginário da história contra a ficção e um texto de fácil assimilação lavrado para o desejado leitor que buscaria na história respostas e máximas com conotação moral. Diferentemente, interessa-nos por meio do uso do aporte da antropologia histórica, da história dos sentidos (Corbin, Sansot) e da subjetividade (Haroche) respeitar a diferença e fazer dialogar os domínios da história e da ficção (Certeau, Bresciani e Sus-

2 Benjamin. GS, V, 1006, F,6 apud BOLLE, W. A metrópole como espaço imagético. In: Fisiognomia da metrópole moderna. São Paulo, EDUSP, 1994, p. 63 
sekind), para que possamos indicar o ritmo da vida urbana, os processos de subjetivação e de espacialização do desejo na cidade.

\section{O HORIZONTE, A ESTÉTICA E A HISTÓRIA}

A história urbana do final dos oitocentos em Minas Gerais é marcada por um jogo de oposições em cujos extremos figuram as cidades de Ouro Preto e de Belo Horizonte. De um lado temos a cidade colonial, Ouro Preto que na bela imagem de Sérgio Buarque de Holanda surge como uma silhueta enlaçando a paisagem. De outro temos a capital republicana fruto de uma geometria racional, no plano de Belo Horizonte o eixo monumental formado pela atual Avenida Afonso Pena é traçado em perspectiva e produz uma bela visada da serra do Curral.

\section{O SUPREMATISMO CRITICA A PERSPECTIVA}

Como peixes fostes capturados na malha do horizonte (Kazimir Malevich).

Em 1913 o pintor Malevich propõe uma nova espacialidade em seu programa do suprematismo e critica a tradição da perspectiva. A citação faz referência à incapacidade do peixe em perceber a rede que o aprisionará. Em nosso caso a linha do desenho em perspectiva articula a representação do espaço a partir do qual Belo Horizonte se estrutura e também os valores estéticos, visuais a ela associados, canône do qual Malevich se propõe libertar.

Como vimos anteriormente, no presente o habitante da capital mineira vivencia uma tensão. Ele observa impotente o acelerado ritmo da dissolução da linha do horizonte do qual se tornou captivo ao longo da história da cidade ao nele reconhecer o marco do lugar em que habita. Henri Michaux em várias passagens de sua obra destaca a angústia e a impossibilidade de se vivenciar a abolição do horizonte. O horizonte sintetiza a rica dinâmica do espaço interior e exterior. Em Belo Horizonte as atividades minerárias ainda que conclusas na serra do Curral a ameaçam mais uma vez fazendo deslizar e descer novamente a linha da cumeada da serra em mais de um quilometro de extensão. De um lado da serra Belo Horizonte, de outro Nova Lima, municipalidades e normas distintas e muitas vezes concorrentes de gestão do espaço que aceleram ainda mais o processo de mutilação da linha do horizonte. Retomamos aqui a grelha da representação em perspectiva que produz o horizonte como seu ponto de fuga.

110 Número temático: Desenho e Educação: Cultura Visual e Cidade. A Cor das Letras - UEFS, n. 
Figura 1 - Belo Horizonte, 1910

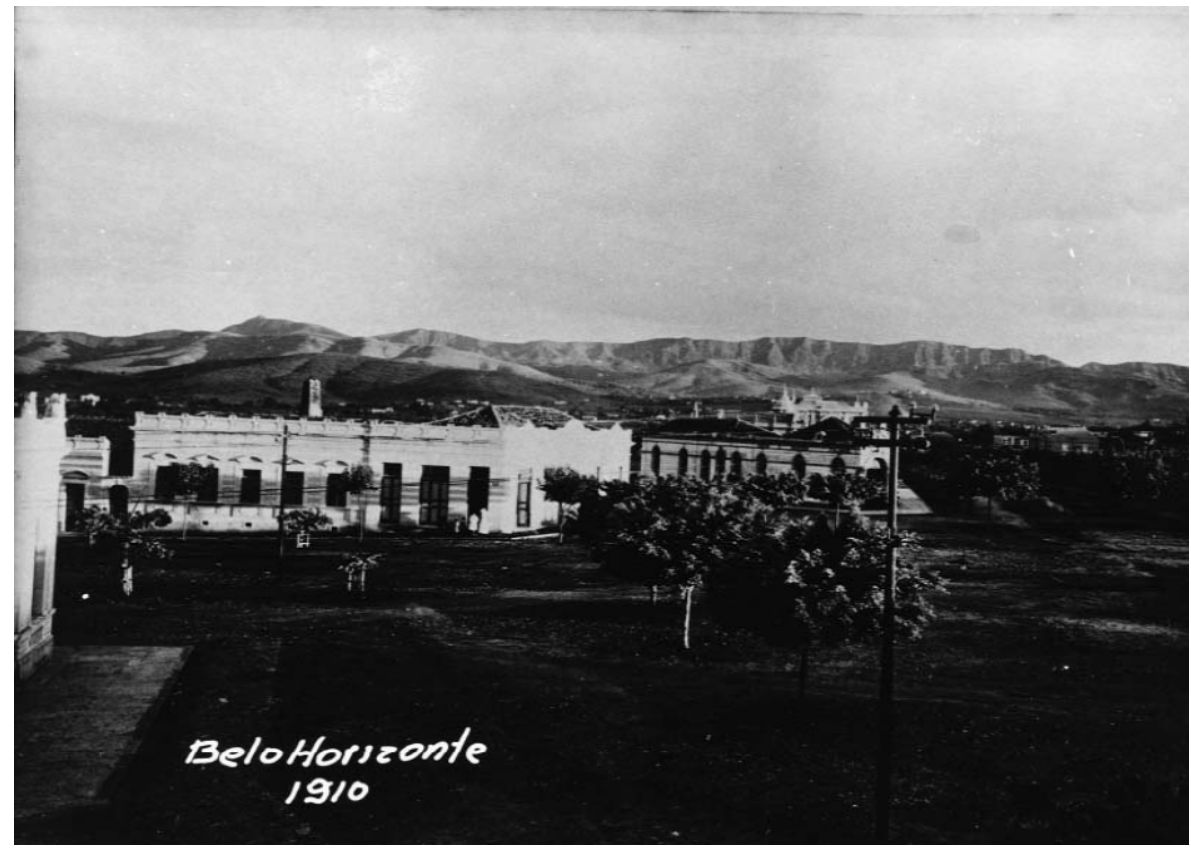

Fonte: APCBH

Repetindo, "o horizonte é mais que uma imagem e menos que um conceito." Por um lado e segundo Céline Flécheux, horizonte vem do grego orismos que significa limite, oros limite do campo materializado por uma pedra ou coluna. O verbo orizo on significa separar por uma fronteira, delimitar, determinar, definir. As derivações segundo essa autora atestam as ligações entre a linguagem e o território. Por outro o suprematismo se propõe a realizar a crítica à hierarquização, à coincidência posta pela perspectiva do infinito como um lugar do horizonte e de forma engajada a fazer desaparecer o ponto de vista único e fixo do burguês na arte. A proposta do movimento é: eliminar o obstáculo que a perspectiva coloca ao cindir sujeito e objeto, quebrar a unicidade do ponto de vista e operar com uma nova espacialidade que adota a reversibilidade, a descentralização e a extensão contra uma concepção disciplinada da visão. O quadro de Lissitzki intitulado Battre les blancs avec la cale rouge ficou como exemplo maior dessa proposta. Tanto o suprematismo quanto a axonometria que será usada pelos 
arquitetos para representar as edificações respondem a percepção que é afetada pelo movimento, pela velocidade.

Figura 2 - Avenida Afonso Pena, o Parque, o córrego Acaba Mundo e o Instituto de Educação, 1902

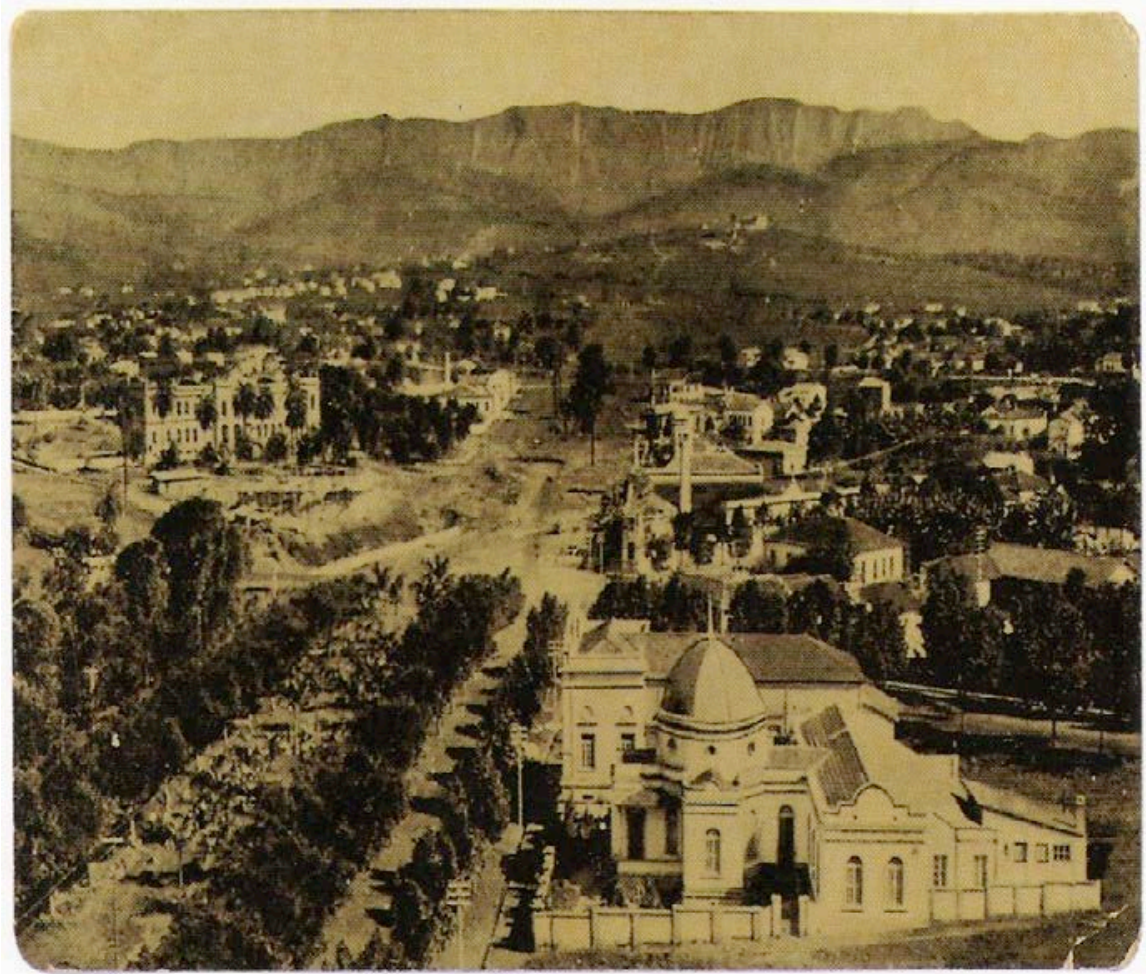

Fonte: Desconhecida APCBH

\section{BELO HORIZONTE E A PERSPECTIVA}

A nova capital de 1897 é construída com o uso de grande terraplanagem na implantação da Praça da Liberdade, sede do Palácio do Governo e a fixação do ponto mais alto da avenida a Praça do Cruzeiro para ser instalada a Matriz, portanto ela segue também a lógica de implantação dos templos e das vias preconizada pela Igreja como norma para a cidade colonial. Se na Paris haussmaniana a via se alinha e aponta para a edificação monumental como é o exemplo da Ópera e da avenida de mesmo nome que lhe dá acesso, na capital de Minas Gerais a serra é o alvo. O topônimo opera a muta112 Número temático: Desenho e Educação: Cultura Visual e Cidade. A Cor das Letras - UEFS, $n$. 
ção do sentido atribuido ao lugar, de espaço fechado que contêm, ou seja de Curral D’El Rey, à cidade de Minas, ele se transforma até se fixar no nome Belo Horizonte.

Figura 3 - Panorama de Belo Horizonte em mapa de 1922

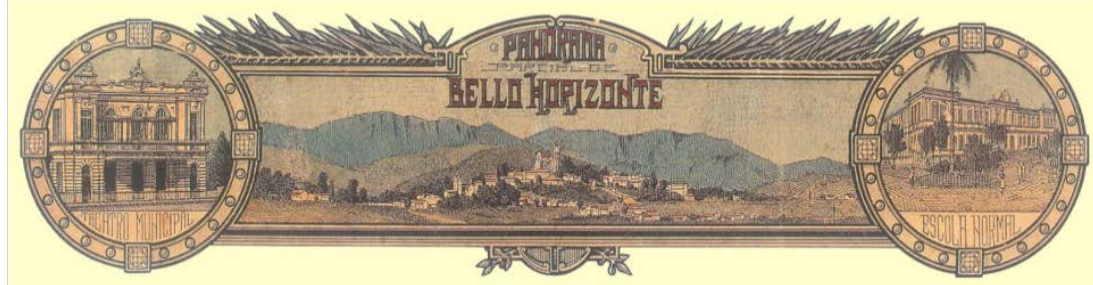

Fonte: Atlas Histórico. Belo Horizonte: FJP, 1997

Figura 4 - Triangulação

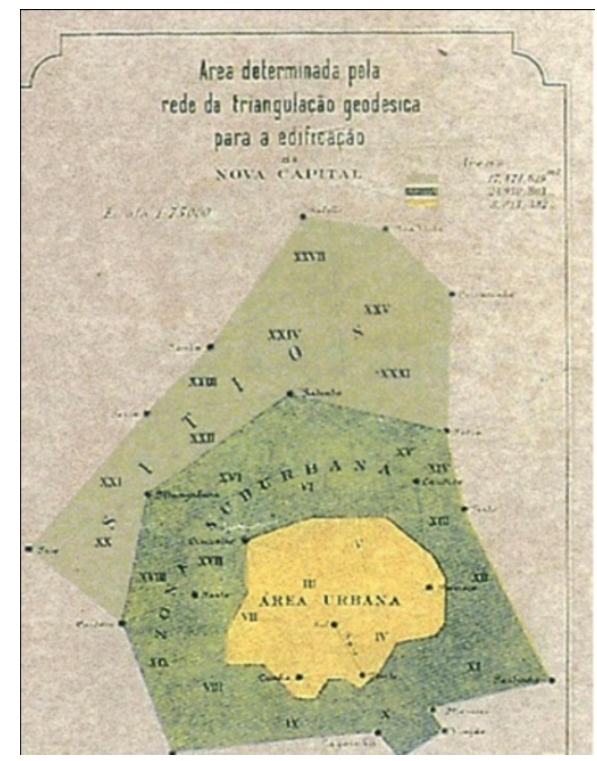

Fonte: Atlas Histórico. Belo Horizonte: FJP, 1997

De seu ponto mais elevado a Praça do Cruzeiro parte a triangulação que estrutura a confecção da planta cadastral e o polígono que delimita a cidade de Belo Horizonte. No sentido contrário na direção sul-norte o declive no traçado das vias foi recurso fundamental para a implantação da rede de distribuição da água concebida pelo engenheiro Saturnino Brito que aproveita a diferença de cota para a circulação da mesma. 
Posição e recorte visual comentado com o fino humor do primeiro cronista de Belo Horizonte, Alfredo Camarate, arquiteto e músico que escreve sob o pseudônimo de Alfredo Riancho:

tudo a deliciosos pontos de vista, e que a localidade se presta a delinear avenidas de alguns quilômetros de extensão e às quais se poderá dar a largura de sessenta metros: que a média do declive, da maior parte das ruas, regulará por três ou quatro por cento, um declive famoso, para o trânsito, para o esgotamento das águas pluviais e para o serviço do esgoto, e que algumas ruas terão talvez $10 \%$ de declive, mas que serão poucas e necessárias para os moradores que consideram as subidas moderadas como altamente vantajosas para a atividade e funções do estomago e para aqueles que, por natural vaidade, gostam de olhar para o próximo, de cima para baixo! ${ }^{3}$

\section{O plano estabelece um sentido:}

Partirá a grande avenida que atravessando quase toda a capital, irá terminar, com percurso de mais de três quilômetros no alto do Cruzeiro, onde será edificada a Igreja que tem de substituir a velha matriz do arraial, [...]

O panorama que dali se descortina, e o eito que deverão fazer os edifícios públicos, que nessa parte alta da cidade serão levantados." Aarão Reis em 1893 vaticina: "apenas uma avenidade cinquenta metros, centro obrigado da cidade ... para forçar a população a se desenvolver do centro para a periferia.

Figura 5 - Av. Afonso Pena, 1930

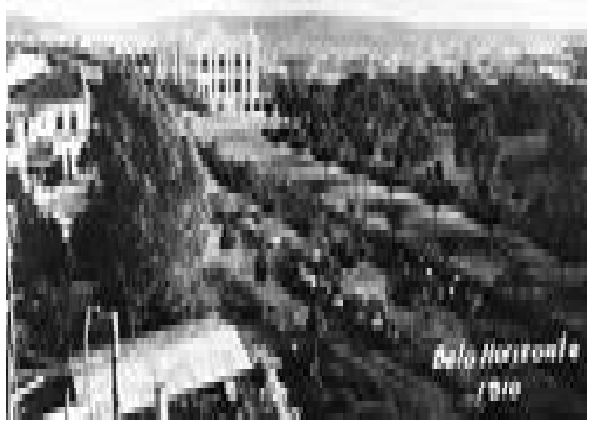

Fonte: APCBH

3 RIANCHO, A. Pelos montes e vales. Revista do Arquivo Público Mineiro, Belo Horizonte, p. 73. 114 Número temático: Desenho e Educação: Cultura Visual e Cidade. A Cor das Letras - UEFS, n. 


\section{O OLHAR}

No final da década de 1920 ocorre a intensificação de uma política municipal de arborização das vias, de implantação de um sistema de distribuição de água que optou pela progressiva e irreversível canalização e o desaparecimento de vários cursos d'água, entre eles o Acaba Mundo que corta a avenida Afonso Pena. Paradoxalmente o crescimento do ficus na avenida Afonso Pena e o adensamento da cobertura vegetal subtrairá do transeunte parte significativa da visada da serra instaurando uma barreira verde e restringindo o alcance do olhar a via e as edificações que a ladeiam. A consolidação do bonde modificou a percepção de seus usuários e participou da formação de uma política de vetores de velocidade (Paul Virilio) dos meios de locomoção na cidade. Nesse momento a avenida articulou uma paisagem rolante e em desfile ou seja a do observador de dentro do veículo ou em ascensão rumo a vista do alto da edificação que ultrapassou em muito a altura da torre da Igreja São José. A ascensão e o mergulho do olhar nesses deslocamentos que ganham velocidade ao longo do tempo correspondeu a um processo de laicização da vista. Por um lado a planejada igreja matriz não foi construida no ponto mais alto da avenida Afonso Pena. Por outro no centro as transformações na avenida Afonso Pena promoveram a reordenação do deslocamento ao redor da Igreja São José (COUTO, 2011).

Figura 6 - Transformação da Avenida e do olhar. Dos Correios ao Sulacap

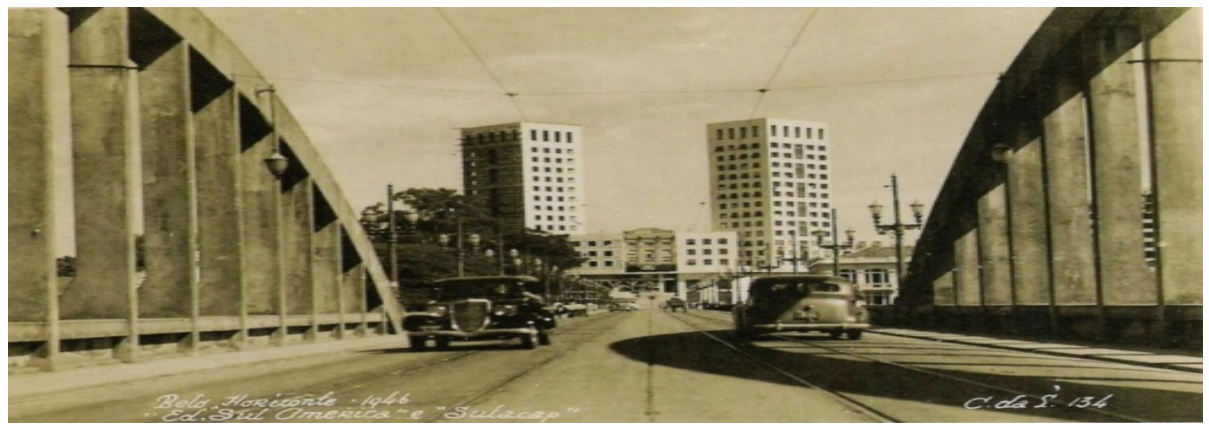

Fonte: $\mathrm{APCBH}$

Em 1933 o aeroporto da Pampulha foi criado destinando-se inicialmente a abrigar o serviço do correio aéreo militar. Paralelamente foi demolida a importante edificação dos correios situada no lado oposto da Igreja São José para dar lugar ao edificio Sul América Capitalização (SULACAP) 
datado de 1946. Detectamos nesse momento e local a intenção de alterar o olhar que se desloca da montanha e se volta para a esquerda. Entre as justificativas usadas na época para a radical substituição das duas edificações estaria o propósito de se recuperar um espaço livre à esquerda da avenida Afonso Pena. Esse vazio figurou na planta cadastral da gestão de Juscelino Kubitschek na Prefeitura. No projeto do SULACAP o vazio se estabelece entre a área vertical edificada das duas torres e enquadraria a visada do viaduto que transpõe a linha férrea conectando a Avenida Tocantis atual Assis Chateaubriand e o bairro Floresta à Avenida Afonso Pena.

O incipiente processo de motorização da vida urbana é incrementado nos anos 1940 com o crescimento da cidade industrial - cuja via de acesso se faz pela Avenida Amazonas via perpendicular da Avenida Afonso Pena que a intercepta na Praça Sete - e o lançamento do mote que se repetirá até o presente de uma suposta vocação minerária e extrativista da região. No perímetro que delimita a figura do Quadrilátero Ferrífero do qual Belo Horizonte e Ouro Preto fazem parte, o futuro ficou aprisionado ao processo de degradação promovido pelo extrativismo que só findará com a exaustão dos recursos minerais e a dissolução da linha do horizonte.

Com relação à Serra do Curral nem o seu tombamento ocorrido em 21 de setembro de 1960, processo 591 - T-58, inscrição 29 A, folha 8, no Livro de Tombo Arqueológico, Etnográfico e Paisagístico que em princípio proporcionaria a proteção da paisagem, nem o artigo 224 da Lei Orgânica do Município de 1990, nem a eleição pela população de símbolo da cidade em 1995 consegue conter a dissolução e a quebra da linha do horizonte. No instrumento de tombamento lemos: Uma faixa de 1800 metros de largura, tendo por eixo o prolongamento do eixo da Avenida Afonso Pena, e delimitada: em baixo, pela linha de nível à cota mil e cem metros; em cima pela linha da cumeada da Serra do Curral. Estende-se de um e outro lado do eixo da Avenida, por duas retas paralelas, cada qual correndo a novecentos metros, por outra compreendida entre a citada linha de nível à cota de $1100 \mathrm{~m}$ e outra à cota de hum mil duzentos e cinquenta metros sem abranger a linha de cumeada, e estendendo-se a estaca 187. O Pico de Belo Horizonte está incluído no tombamento, desde o seu cume até a cota de hum mil duzentos e cinquenta metros onde se junta com a faixa descrita acima. 


\section{“O RITO DE CIDADE”}

De um lado temos a mineração sobre a qual Carlos Drummond na década de 1970 após o tombamento da Serra escreveu o conhecido lamento:

Tento fugir da própria cidade, reconfortar-me em seu austero píncaro serrano [...] em vão tento a escalada. Cassetetes e revólveres me barram a subida que era a alegria dominical de minha gente. Proibido escalar. Proibido sentir o ar de liberdade destes cismos, proibido viver a selvagem intimidade destas pedras que se vão desfazendo em forma de dinheiro. Esta serra tem dono. Não mais a natureza a governa. Desfaz-se com o minério uma antiga aliança, um rito de cidade (g. n. $)^{4}$.

E de outro temos a escalada imobiliária em ampla expansão em direção a linha da cumeada. A esse duplo avanço ascendente se soma a instalação em seu topo de um conjunto de antenas.

Os atores responsáveis pela gestão da cidade moldaram uma explicação simples e linear. $O$ crescimento da cidade pediu novos dispositivos de comunicação e as antenas da Polícia destinadas à segurança de seus habitantes tornam um imperativo a sua instalação na cumeada da serra. Notamos aqui que, se por um lado a lógica da Igreja de destinar o topo da montanha aos templos é rompida, por outro o discurso ambientalista se empenha em garantir intacta a cumeada da serra devido a importância dessa área na recarga de nascentes que alimentam os cursos d'água que abastecem a cidade. Como um sintoma apontamos que, ao tratar da mudança operada pela antenas não há ponderação, eles não indagam se, entre as variadas serras na região, haveria outro local possível de instalação de antenas que não incidisse na paisagem serrana da capital. Uma das argumentações construídas para justificar a transformação foi a de fazer coincidir no nível discursivo três elementos distintos e a partir do discurso estabelecer uma rede de inferências no âmbito do ordenamento da cidade. Desloca-se para o mesmo ponto, primeiro a instalação do objeto técnico, a antena que é identificada à defesa de um direito humano fundamental, a vida, e em seguida o direito à vida que nessa interpretação espelha-se no direito à segurança e esse por sua vez e por último no direito à comunicação que as torres materializam. E refletimos, subtrai-se o valor da serra em nome de uma interpretação e de uma negação do sentido do tombamento.

4 ANDRADE, C. Triste horizonte. Discurso de primavera e outras sombras. Rio de Janeiro, J. Olympio, 1978, p. 11-16. 
A linha da cumeada da serra desliza em um processo de anamorfose que acaba por delinear a forma de um paliteiro com as antenas e a verticalização de edificações no seu entorno. Talvez a imagem da serra e dos prédios do bairro Belvedere e de Nova Lima obtida de vários pontos da região metropolitana de Belo Horizonte reverbere na afetuosa acolhida por parte de seus habitantes da obra Beam Drop (2008) de Chris Burden do acervo do Museu Inhotim.

Pois se como assinala Simmel: "Para que nasça a paisagem, é necessária inegavelmente que a pulsação da vida, na percepção e no sentimento, seja arrancada da homogeneidade da natureza" ${ }^{5}$ e face a angustia e a impossível experiência da dissolução do horizonte, recortamos a citação inicial de Malevich para encerrar o nosso texto: "como peixes" mineiros, "fostes capturados na malha do horizonte".

A leitura das narrativas da cidade visa portanto acompanhar a circulação de palavras tais como tempo, memória, fronteira, limite, horizonte, mineração. Nesse processo acreditamos que será possível de um lado perceber pelo meio do material crítico e da liberdade com a qual o texto literário opera, pistas e indícios de como a sociedade mineira constrói estereótipos que vinculam o homem e a paisagem como uma matriz de imagens que é reproduzida na história da capital e de outro, a partir da experiência de leitura da ficção propor uma crítica que revele os sentidos associados à história do horizonte.

\section{REFERÊNCIAS}

ANDRADE, Carlos Drummond de. Poesia e prosa. 6. ed. rev. e atual. Rio de Janeiro: Nova Aguilar, 1988.

ANDRADE, Carlos Drummond de. Triste horizonte. Discurso de primavera e outras sombras. Rio de Janeiro: J. Olympio, 1978.

ANDRADE, Rodrigo; MAGALHÃES, Beatriz. Belo Horizonte: um espaço para a república. Belo Horizonte: UFMG, 1989

BARRETO, Abilio. Belo Horizonte - memória histórica e descritiva. Belo Horizonte: CEHC Fundação João Pinheiro, 1994.

BENJAMIN, Walter. Correspondance, 1929-1940. Paris: Aubier Montagne, 1979.

BOLLE, Willy. Fisiognomia da metrópole moderna. São Paulo: Edusp, 1994.

BOLLE, Willy. Fisiognomia da metrópole urbana. São Paulo: Edusp, 2000.

5 SIMMEL. Philosophie du paysage. In: Op cit., p. 234.

118 Número temático: Desenho e Educação: Cultura Visual e Cidade. A Cor das Letras - UEFS, n. 
BRESCIANI, Maria Stella Martins. (Org.). Imagens da cidade - séculos XIX e XX. São Paulo: ANPUH; Marco Zero/Fapesp, 1994.

BRESCIANI, Maria Stella Martins. (Org.). Palavras da cidade. Porto Alegre: UFRGS, 2001.

BRESCIANI, Maria Stella Martins. Literatura e cidade. In: CARDOSO, Selma Passos; PINHEIRO, Eloísa Petti; CORRÊA, Elyane Lins. (Org.). Arte e cidades. Imagens, discursos e representações. Salvador: Ed.UFBA, 2008, p. 9-40.

BRESCIANI, Maria Stella Martins. Londres e Paris: o espetáculo da pobreza. São Paulo: Brasiliense, 1980.

BRESCIANI, Maria Stella Martins. Londres e Paris: o espetáculo da pobreza. São Paulo: Brasiliense, 1981.

BRESCIANI, Maria Stella Martins. A cidade: objeto de estudo e experiência vivenciada. Revista Brasileira de Estudos Urbanos e Regionais, 2011.

BRESCIANI, Maria Stella Martins. Literatura e cultura no Brasil: identidades e fronteiras. São Paulo: Cortez, 2002.

BRITO, S. Tracé sanitaire des Villes (tecnique sanitaire urbaine). Paris: Imprimerie Chaix, 1916.

CAMILOTTI, Virginia. História e literatura: fontes literárias na produção historiográfica recente no Brasil. História: Questões e Debates, Curitiba, n. 50, p. 15-49, jan./jun. 2009.

CAUQUELIN, A. Essai de philosophie urbaine. Paris: PUF, 1982.

COUTO, Beatriz. Igreja São José: o eclipse de sua imagem em Belo Horizonte no século XX. Arquitextos, São Paulo, Portal Vitruvius, fev. 2012.

DAMAZIO, Reinaldo. Drummond revisitado. São Paulo: Unimarco, 2002.

DELSON, Max. Novas Vilas para o Brasil-Colônia: planejamento espacial e social no século XVII. Brasília: Alva Ciord, 1977.

DIAS, Márcio Roberto Soares. Da cidade ao mundo: notas sobre o lirismo urbano de Carlos Drummond de Andrade. Vitória da Conquista: Edições Uesb, 2006.

DUARTE, Regina Horta. À sombra do ficus. Cidade e natureza em Belo Horizonte. Ambiente e Sociedade, Campinas, UNICAMP/NEPAM, v. 10, n. 2, p. 25-44, dez. 2007.

FUNDAÇÃO JOÃO PINHEIRO. Belo Horizonte: Bilhete postal. Coleção Otávio Dias F. Belo Horizonte: FJP, 1997.

GINSBURG, Carlo. Mitos, emblemas, sinais. In: Morfologia e história. São Paulo: Cia. das Letras, 1989.

GSPAPIECINSKI, Marlise. Sujeito e modernidade na poética de Carlos Drummond. O Eixo e a Roda - Revista de Literatura Brasileira, Belo Horizonte, FALE/UFMG, v. 8, p. 165-182, 2002.

GUATTARI, Felix. O inconsciente maquínico. Campinas: Papirus, 1988.

HOLANDA, Sérgio Buarque de. Raízes do Brasil. São Paulo: Cia. das Letras, 1995.

JANKÉLÈVITCH SIMMEL, George. La tragédie de la culture. Paris: Rivages, 1988

JULIAO, L. Sensibilidades e representações urbanas na transferência da Capital de Minas Gerais. História, São Paulo, v. 30, n. 1, p. 114-147, jan-jun. 2011.

LIMA, Luiz Costa. O controle do imaginário. São Paulo: Cia. das Letras, 2009. 
LOPES, Myriam Bahia. Ladeira. In: TOPALOV. L'aventure les mots de la ville. Paris: Robert Laffont, 2010.

MARTINS, Wilson. Temas drummondianos. In: BRAYNER, Sônia. (Org.). Carlos Drummond de Andrade: fortuna crítica. Rio de Janeiro: Civ. Brasileira, 1978, p. 266-72.

OLIVEIRA, Lúcia Lipi. (Org.). Cidade e história. In: Cidade: história e desafios. Rio de Janeiro: FGV, 2002.

PANORAMA de Belo Horizonte. Atlas histórico. Belo Horizonte: FJP/CEHC, 1997.

RIBEIRO, S. M. A. O espaço público em BH. A Av Afonso Pena como lugar de sua manifestação. Belo Horizonte, Mestrado NPGAU EA UFMG, 2000.

SALGUEIRO, Heliana Angoti. Le casaque d'Arlequin. Paris: EHESS, 1997.

SILVA, R Helena Alves da; FENELON, Déa Ribeiro. A cidade de Minas. 161 f. Dissertação (mestrado) - Universidade Federal de Minas Gerais, Departamento de Ciência Política, 1991.

SIMMEL, Georges. Les grandes villes et la vie de l'esprit. Paris: L'Herne, 2007.

SIMMEL, Georges. Simmel a estética e a cidade. Coimbra: Universidade de Coimbra, 2010.

WISNIK, José M. Drummond e o mundo. In: NOVAES, Adauto. Poetas que pensaram o mundo. São Paulo, Cia. das Letras, 2005. 